\section{Kidney \\ Blood Pressure Research}

\title{
Serum Protein Thiol Levels in Patients with Hospital-Acquired Acute Kidney Injury
}

\author{
Jing Qian ${ }^{\mathrm{a}, \mathrm{b}} \quad$ Junyan Fang ${ }^{\mathrm{a}}$ Qiuyu Zhu ${ }^{\mathrm{a}}$ Shuai Ma ${ }^{\mathrm{a}, \mathrm{b}} \quad$ Wenji Wang ${ }^{\mathrm{a}}$ \\ Ying Zheng ${ }^{a, b}$ Guihua Hao ${ }^{a}$ Bo Denga,b Xiaojiao Zhao ${ }^{a}$ Feng Ding ${ }^{a}$ \\ aDivision of Nephrology, the Ninth People's Hospital, School of Medicine, Shanghai Jiaotong University, \\ bDivision of Nephrology, Huashan Hospital, Fudan University, Shanghai, China
}

\section{Key Words}

Acute kidney injury $\bullet$ Serum protein thiols $•$ Mortality

\begin{abstract}
Background/Aims: This study aimed to examine antioxidants in patients with acute kidney injury (AKI) and determine whether serum protein thiol levels are associated with all-cause 90-day mortality in patients with hospital-acquired AKI. Methods: According to the RIFLE criteria, 160 patients with hospital-acquired AKI were enrolled in our prospective cohort study. As controls, 72 critically ill patients without AKI and 72 age and sex-matched healthy subjects were also recruited. Serum protein thiol levels were analyzed in relation to all-cause mortality of patients with AKI. Results: Serum protein thiol levels in AKI patients were lower than those in healthy people $(p=0.010)$. Protein thiol levels showed a weak but significant positive correlation with serum albumin levels. The 90 -day overall mortality rate was higher in AKI patients with high serum protein thiol levels than in those with low levels ( $p=0.032$ by log rank test). In multivariate analysis (Cox regression), serum protein thiol levels $(p=0.031$ ) were independently associated with 90-day overall mortality after adjustment for age, sex, sepsis, and the Acute Physiology and Chronic Health Evaluation II score. Conclusions: Patients with hospital-acquired AKI have remarkably low serum protein thiol levels. Elevated protein thiol levels are associated with 90-day overall mortality in hospital-acquired AKI.
\end{abstract}

Copyright (c) 2015 S. Karger AG, Basel

\section{Introduction}

The effect of increased oxidative stress on a high mortality rate of patients who develop acute kidney injury (AKI) has been investigated in recent studies [1]. Systemic inflammatory response syndrome, metabolic derangement caused by hypercatabolism, and multiple organ system failure are prevalent in AKI patients. A reduction in renal clearance of hypercatabolism

J. Qian and J.Y. Fang contributed equally to this work and therefore share first authorship.

Feng Ding, MD 


\section{Kidney Blood Pressure Research}

and inflammatory by-products can exacerbate these systemic disorders. In inflammatory disorders, stimulated phagocytic cells, which produce excess cytokines, are major producers of reactive oxygen species. Renal failure itself is recognized as an additional stimulus for increased oxidative stress $[2,3]$.

The single thiol of serum albumin is the most abundant plasma thiol [4] and it is reduced by $75 \%$. It is usually considered a vital target for electrophiles and oxidants because of its reactivity with a wide variety of species and its relatively high concentration [5]. Therefore, serum protein thiols are a type of biomarker in oxidative stress. However, few clinical studies have examined the prevalence of oxidative stress in patients with AKI, and no studies have examined the association between serum protein thiols and the prognosis of AKI.

We conducted the present study to investigate whether protein thiol levels are elevated or suppressed in AKI patients and whether they are associated with 90-day overall mortality in this population.

\section{Patients and Methods}

This retrospective cohort study was conducted between February 2009 and January 2010 at an affiliated hospital in Shanghai, China.

\section{Selection of participants}

Patients with hospital-acquired AKI. A total of 160 adult patients who were aged $\geq 18$ years old were recruited in the study, according to the Risk, Injury, Failure, Loss, or End stage (RIFLE) staging criteria [6]. Exclusion criteria included the following: 1) confirmed and/or suspected acute glomerulonephritis, acute interstitial nephritis, renal vasculitis or postrenal etiology for AKI; 2) diagnosis of metastasis of tumors; 3) admission with AKI; 4) a premorbid increase in serum creatinine levels from an unknown cause; 5) enrollment in other studies; 6) pregnancy; and 7) use of antioxidants. Table 1 shows the baseline demographic and biochemical characteristics of patients with AKI.

Critically ill patients without AKI. Seventy-two critically ill patients without AKI were also enrolled from the hospital as control subjects. All of them were matched in age, sex, and Acute Physiology and Chronic Health Evaluation (APACHE) II score with the AKI patients.

Healthy subjects. A group of 72 age and sex-matched healthy subjects were also enrolled as controls. They were randomly recruited from healthy subjects of a healthcare center of the hospital.

This study was approved by the ethics committee of the hospital (approval number: 2009-097). All of the patients provided written informed consent and the Declaration of Helsinki was adhered to.

\section{Study definitions}

AKI was determined using the RIFLE classification criteria [6]. Patients were diagnosed and classified based on changes in serum creatinine levels from baseline to diagnosis of AKI, rather than the maximal creatinine level during hospitalization. The baseline serum creatinine level was defined as the lowest serum creatinine level within 1 week prior to diagnosis of AKI. Sepsis syndrome was considered to be present in patients in whom infection was accompanied by at least two systemic inflammatory response syndrome criteria, according to consensus guidelines. Infection was diagnosed according to usual clinical syndromes, laboratory results, and microbiological parameters. Patients with operations were defined as those who had undergone a surgical operation within 1 week before diagnosis of AKI.

\section{Clinical evaluation and primary outcome}

Clinical evaluation was recorded at the time of diagnosis of AKI in patients with AKI and at the time of enrollment in control groups, unless otherwise noted. Baseline demographics, including age, sex, and comorbidities, such as hypertension, diabetes mellitus, cardiovascular disease, chronic hepatic disease, chronic kidney disease, chronic obstructive pulmonary disease, and malignant tumors, were recorded. Upon enrollment of the patients, we also recorded the following: the possible cause of AKI, the presence of sepsis, and need for mechanical ventilation. The APACHE II score was used to assess the degree of organ dysfunction. 


\section{Kidney Blood Pressure Research}

Table 1. Baseline demographic and clinical data of patients at the time of diagnosis of acute kidney injury stratified by RIFLE stages

\begin{tabular}{|c|c|c|c|c|c|}
\hline \multirow[b]{2}{*}{ Characteristic } & \multicolumn{5}{|c|}{ No. $(\%)$} \\
\hline & $\begin{array}{c}\text { Total } \\
(\mathrm{n}=160)\end{array}$ & $\begin{array}{c}\text { Risk } \\
(\mathrm{n}=70)\end{array}$ & $\begin{array}{l}\text { Injury } \\
(\mathrm{n}=38)\end{array}$ & $\begin{array}{l}\text { Failure } \\
(\mathrm{n}=52)\end{array}$ & $\begin{array}{c}p \\
\text { value }\end{array}$ \\
\hline Age (yr), mean (s.d.) & $62.8 \pm 18.1$ & $65.9 \pm 16.7$ & $66.6 \pm 17.2$ & $55.9 \pm 19.3$ & 0.060 \\
\hline Sex $(\%$ female $)$ & $48(30.0)$ & $20(28.6)$ & $14(36.8)$ & $14(26.9)$ & 0.750 \\
\hline Baseline Scr (mg/dL) & $0.70 \pm 0.25$ & $0.75 \pm 0.23$ & $0.67 \pm 0.17$ & $0.64 \pm 0.33$ & 0.300 \\
\hline $\begin{array}{l}\text { Scr when AKI diagnosed } \\
(\mathrm{mg} / \mathrm{dL})\end{array}$ & $1.53(1.21,2.10)$ & $1.25 \pm 0.39$ & $1.63 \pm 0.39$ & $3.82 \pm 3.3$ & $<0.001$ \\
\hline \multicolumn{6}{|l|}{ Comorbid conditions } \\
\hline Hypertension (\%) & $76(47.5)$ & $32(45.7)$ & $21(55.3)$ & $23(44.2)$ & 0.715 \\
\hline CVD (\%) & $22(13.5)$ & 11(15.7) & $6(15.8)$ & $5(9.6)$ & 0.710 \\
\hline $\mathrm{DM}(\%)$ & $22(13.8)$ & $12(17.1)$ & $4(10.51)$ & $6(11.5)$ & 0.919 \\
\hline Chronic hepatic disease (\%) & $9(5.6)$ & $4(5.7)$ & $0(0)$ & $5(9.6)$ & 0.462 \\
\hline Malignant tumor (\%) & $15(9.4)$ & $6(8.6)$ & $4(10.5)$ & $5(9.6)$ & 0.962 \\
\hline COPD & $6(3.8)$ & $2(2.9)$ & $2(5.3)$ & $2(3.8)$ & 0.906 \\
\hline CKD $(\%)$ & $2(1.3)$ & $0(0)$ & $0(0)$ & $2(3.8)$ & 0.325 \\
\hline \multicolumn{6}{|l|}{ AKI etiology } \\
\hline Ischemic (\%) & $59(36.9)$ & $23(32.9)$ & $18(47.4)$ & $18(34.6)$ & 0.534 \\
\hline Nephrotoxic (\%) & $51(31.9)$ & $25(35.7)$ & $12(31.6)$ & $14(26.9)$ & 0.788 \\
\hline Others (\%) & $50(31.2)$ & $22(31.4)$ & $8(21.0)$ & $20(38.5)$ & \\
\hline Operation (\%) & $83(51.9)$ & $49(70.0)$ & $18(47.4)$ & $16(30.8)$ & 0.008 \\
\hline Sepsis $(\%)$ & $67(41.9)$ & $29(41.4)$ & $18(47.4)$ & $20(38.5)$ & 0.832 \\
\hline Mechanical ventilation (\%) & $65(40.6)$ & $20(28.6)$ & $18(47.4)$ & $27(51.9)$ & 0.149 \\
\hline MAP (mmHg) & $89 \pm 18$ & $91 \pm 15$ & $86 \pm 17$ & $88 \pm 22$ & 0.608 \\
\hline $\mathrm{WBC}\left(\times 10^{3} / \mu \mathrm{L}\right)$ & $12.8 \pm 6.6$ & $12.3 \pm 6.3$ & $15.1 \pm 6.9$ & $12.0 \pm 6.6$ & 0.237 \\
\hline Neutrophilic granulocyte (\%) & $82.5(76.2,86.7)$ & $81.5(73.2,85.6)$ & $82.4 \pm 9.45$ & $79.6 \pm 16.4$ & 0.361 \\
\hline Hemoglobin $(\mathrm{g} / \mathrm{dL})$ & $11.0 \pm 2.7$ & $11.4 \pm 2.0$ & $11.1 \pm 2.8$ & $10.5 \pm 3.5$ & 0.405 \\
\hline Platelet $\left(\times 10^{3} / \mu \mathrm{L}\right)$ & $138.4 \pm 89.8$ & $148.7 \pm 88.6$ & $138.4 \pm 77.3$ & $124.5 \pm 100.4$ & 0.588 \\
\hline $\operatorname{ALT}(\mathrm{U} / \mathrm{L})$ & $32.0(18.0,63.0)$ & $28.0(18.5,58.5)$ & $38.0(20.0,73.0)$ & $31.5(13.0,98.0)$ & 0.487 \\
\hline $\operatorname{AST}(\mathrm{U} / \mathrm{L})$ & $38.0(23.0,91.0)$ & $34.5(22.7,71.0)$ & $63.0(28.0,145.0)$ & $44.0(18.0,113.7)$ & 0.207 \\
\hline Serum albumin $(\mathrm{g} / \mathrm{dL})$ & $3.2 \pm 0.7$ & $3.5 \pm 0.7$ & $3.3 \pm 0.7$ & $2.9 \pm 0.7$ & 0.001 \\
\hline Serum total calcium $(\mathrm{mmol} / \mathrm{L})$ & $2.1 \pm 0.3$ & $2.1 \pm 0.2$ & $2.0 \pm 0.3$ & $2.0 \pm 0.3$ & 0.217 \\
\hline Serum phosphate $(\mathrm{mmol} / \mathrm{L})$ & $1.3 \pm 0.7$ & $1.1 \pm 0.6$ & $1.4 \pm 0.8$ & $1.7 \pm 0.8$ & 0.062 \\
\hline Cholesterol $(\mathrm{mmol} / \mathrm{L})$ & $3.5 \pm 1.5$ & $3.4 \pm 1.4$ & $3.5 \pm 1.8$ & $3.5 \pm 1.4$ & 0.925 \\
\hline Prealbumin $(\mathrm{mg} / \mathrm{dL})$ & $14.4 \pm 6.0$ & $15.5 \pm 6.4$ & $14.7 \pm 6.8$ & $12.7 \pm 4.8$ & 0.212 \\
\hline $\mathrm{CRP}(\mathrm{mg} / \mathrm{dL})$ & $9.2 \pm 7.0$ & $7.5 \pm 6.9$ & $9.9 \pm 7.4$ & $11.3 \pm 6.4$ & 0.114 \\
\hline APACHE II & $20.4 \pm 9.6$ & $15.5 \pm 8.2$ & $23.0 \pm 7.9$ & $25.1 \pm 9.8$ & $<0.001$ \\
\hline
\end{tabular}

Note: Data were obtained at the time of diagnosis of AKI, unless otherwise noted.

Abbreviations: RIFLE, Risk, Injury, Failure, Loss, or End-stage kidney disease staging criteria; CVD, cardiovascular disease; $\mathrm{DM}$, diabetes mellitus; COPD, chronic obstructive pulmonary disease; CKD, chronic kidney disease; Scr, serum creatinine; AKI, acute kidney disease; MAP, mean arterial pressure; WBC, white blood cell; ALT, alanine aminotransferase; AST, aspartate aminotransferase; CRP, C-reactive protein; APACHE II, Acute Physiology and Chronic Health Evaluation II.

All of these patients were followed up for 90 days. The primary outcome was in-hospital all-cause mortality. None of the participants were receiving medications that are known to interfere with oxidative stress, including vitamin C/E or reduced glutathione, during the 90-day follow-up. All of the patients remained under the care of the hospital unit to which they were admitted. Study investigators did not participate in medical care unless invited.

\section{Measurement of serum protein thiols}

Blood samples for serum protein thiol measurements were drawn into BD Vacutainer serumseparating tubes that contained a clot activator at the time of diagnosis of AKI in patients with AKI and at the time of enrollment in the control groups. Protein was first separated by centrifugal ultrafiltration (Millipore Amicon® Ultra -0.5, Ultracel-3 Membrane, $3 \mathrm{kDa}$ ). Quantification of serum protein thiols was then performed using a thiol and sulfide quantitation kit (T6060; Invitrogen Life Technologies) according to the manufacturer's instructions. Serum protein thiol levels are expressed as $\mu \mathrm{M}$ as recommended by the manufacturer.

\section{Statistical analyses}

Normally distributed variables are expressed as mean \pm standard deviation (SD) and were compared using one-way ANOVA or the $t$ test. Non-normally distributed variables are expressed as medians with 


\section{Kidney \\ Blood Pressure Research}

Kidney Blood Press Res 2015;40:623-629

DOI: 10.1159/000368538

Publisned ontIne: vecember 17, 2015

(C) 2015 S. Karger AG, Basel

www.karger.com/kbr

626

quartile ranges and were compared using the rank sum test. Categorical variables are expressed as percentages and were compared using the Pearson chi-squared test or Fisher's exact test. Correlations among continuous data were performed by Pearson correlation coefficients. In multivariate analysis, Cox proportional hazards regression was used to identify independent predictors of mortality in AKI patients. Covariates including age, sex, sepsis, and the APACHE II score were used for stepwise adjustment. Overall survival at 90 days between the high and low groups, which were divided according to the median of serum protein thiol levels, was analyzed using Kaplan-Meier methods. The difference between these two groups was tested using the log-rank test. The event was defined as death and cases lost to follow-up were censored at their last observation. All tests were two-tailed and statistical significance was defined as $p<0.05$. The SPSS statistical software program (version 17.0, SPSS) was used for all analyses.

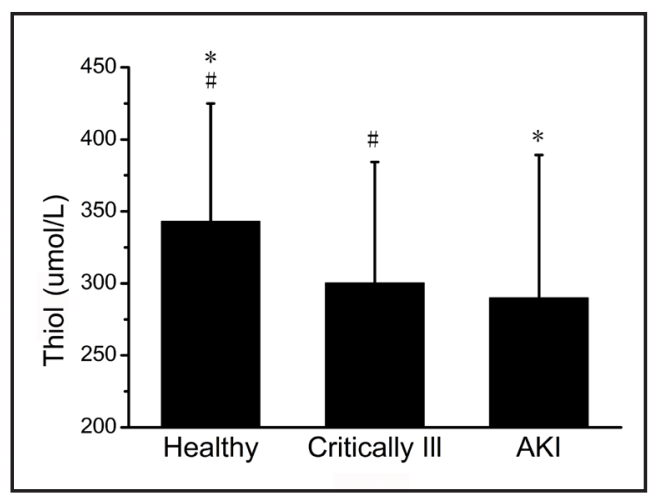

Fig. 1. Thiol levels among healthy subjects, critically ill patients without AKI, and patients with AKI. " $t$ test ( $p=0.044)$, critically ill patients compared with healthy subjects; *t test ( $p=0.005)$, AKI patients compared with healthy subjects.

\section{Results}

Baseline demographic and clinical characteristics of the AKI cohort

A total of 160 patients ( 112 males and 48 females) were enrolled in our study. The mean age of the AKI cohort was $62.8 \pm 18.1$ years. Seventy (43.8\%) patients reached the RIFLE risk stage, $38(23.7 \%)$ reached the RIFLE injury stage, and $52(32.5 \%)$ reached the RIFLE failure stage. The demographic and clinical characteristics stratified by the RIFLE stage of AKI are shown in Table 1. The predominant comorbid conditions of the AKI cohort were as follows: hypertension in $76(47.5 \%)$ patients, cardiovascular diseases in $22(13.8 \%)$, diabetes mellitus in 22 (13.8\%), chronic hepatic disease in nine (5.6\%), non-metastasis malignant tumors in $15(9.4 \%)$, chronic obstructive pulmonary disease in six (3.8\%) and chronic kidney disease in two (1.3\%). Of the 160 AKI patients, 83 (51.9\%) underwent surgery and 67 (41.9\%) suffered from sepsis. The median serum creatinine level was $0.70 \mathrm{mg} / \mathrm{dL}$ at admission, increasing to $1.53 \mathrm{mg} / \mathrm{dL}$ when AKI was diagnosed. The mean APACHE II score was 20.4 9 .6. Seventy-eight (48.7\%) patients died within 90 days after diagnosis of AKI.

Thiol levels in healthy subjects, critically ill patients without AKI, and AKI patients

The mean ages of healthy subjects, critically ill patients without AKI, and patients with AKI were $55.5 \pm 18.2,60.0 \pm 12.7$, and $62.8 \pm 18.1$ years, and the proportion of females was $38.9 \%, 38.9 \%$, and $30.0 \%$, respectively. There were no significant differences in age and sex among the three groups ( $p>0.05)$. The APACHE II score of critically ill patients without AKI was similar to that of patients with AKI $(p>0.05)$.

Figure 1 shows serum protein thiol levels among healthy subjects, critically ill patients without AKI, and patients with AKI. There was a significant difference in serum protein thiol levels among healthy subjects, critically ill patients without AKI, and patients with AKI (ANOVA, $p=0.017)$.Serum protein thiol levels in AKI patients $(290.1 \pm 99.1 \mu \mathrm{mol} / \mathrm{L})$ were lower than those in healthy subjects $(343.2 \pm 81.8 \mu \mathrm{mol} / \mathrm{L})$, but similar to those of critically ill patients $(300.3 \pm 84.0 \mu \mathrm{mol} / \mathrm{L})$.

Thiol levels in patients with AKI of different stages by the RIFLE staging criteria

By RIFLE staging criteria, all of the patients with AKI were classified into three subgroups (risk, injury, and failure) according to their changes in serum creatinine levels 


\section{Kidney \\ Blood Pressure Research}

\section{Kidney Blood Press Res 2015;40:623-629}

DOI: 10.1159/000368538

Publisned ontIne: vecember 17, 2015

(C) 2015 S. Karger AG, Basel

www.karger.com/kbr within 1 week. The sample size of each subgroup was $70(43.8 \%), 38(23.7 \%)$, and $52(32.5 \%)$, respectively. No significant differences in age, sex, and comorbid conditions were found among the three subgroups. The percentage of operations and serum albumin levels were highest in patients in the risk stage and lowest in those in the failure stage $(p=0.008$, $p=0.001)$. The APACHE II scores increased with the severity of AKI $(p<0.001)$. The demographic and clinical characteristics of the three groups are shown in Table 1.

Serum protein thiol levels were $289.1 \pm 101.3,333.6 \pm 103.5$, and $260.1 \pm 85.8$ $\mu \mathrm{mol} / \mathrm{L}$ in risk, injury and failure stage, which showed no correlation with the severity of AKI (ANOVA, $p=0.088$; Fig. 2).

Correlations of serum thiol levels with serum albumin and creatinine levels and the APACHE II score

Serum protein thiol levels showed a weak, but significant, positive correlation with serum albumin levels $(r=0.293$, $p=0.005)$. However there was no significant correlation of serum protein thiol levels with serum creatinine levels or the APACHE II score.

\section{Predictability of thiol levels for 90-day} mortality

The median value of serum protein thiol levels was used as a cut-off point to divide them into another two groups: the low thiol level group $(<274 \mu \mathrm{mol} / \mathrm{L})$ and the high thiol level group $(\geq 274 \mu \mathrm{mol} / \mathrm{L})$.

A total of $59.5 \%$ of patients with high thiol levels died compared with $41.8 \%$ in the group with low thiol levels. According to the Kaplan-Meier plot (Fig. 3), the survival curves of patients with high thiol levels showed significant difference

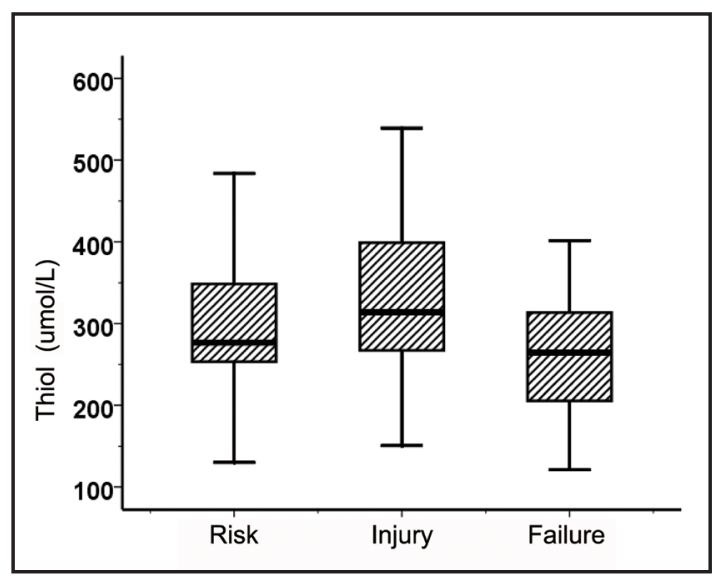

Fig. 2. Thiol levels in 160 patients with AKI stratified by RIFLE stages. $p=0.088$ by ANOVA.

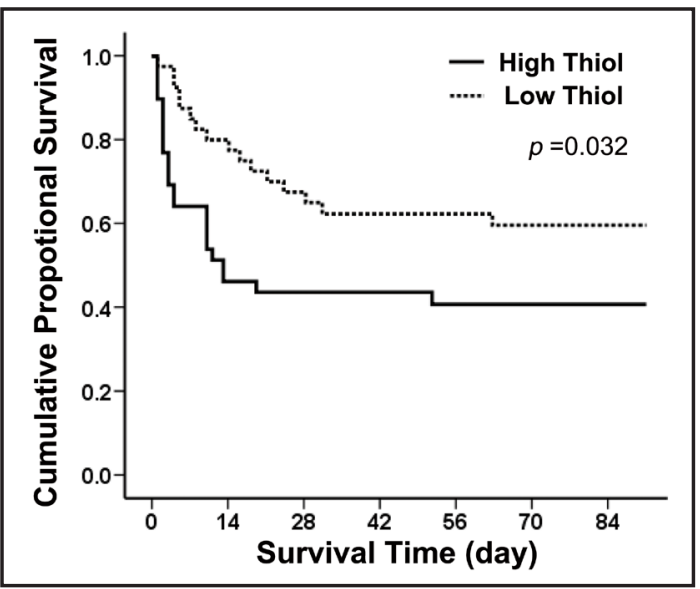

Fig. 3. Kaplan-Meier analysis for the cumulative percentage of surviving patients at 90 days according to different thiol subgroups. Kaplan-Meier plots for probability of survival at 90 days between the high and low thiol subgroups. A significant difference between the two subgroups was found (log rank, $p=0.032$ ).

compared with those with low thiol levels. The mortality rate was significantly higher in the group with high thiol levels than in the group with low thiol levels at 90 days after diagnosis of AKI ( $p=0.032$ by log rank test; Fig. 3).

In multivariable analysis, we controlled for age and sex as model 1, age, sex, and the APACHE II score as model 2, age, sex, and sepsis as model 3, and age, sex, the APACHE II score, and sepsis as model 4 . These variables were selected as possible predictors for mortality of AKI patients. When adjusted for age, sex, sepsis, and the severity of illness (APACHE II score), serum protein thiol levels remained an independent predictor of 90-day overall mortality $(p=0.031$, Table 2$)$. 


\section{Kidney \\ Blood Pressure Research}

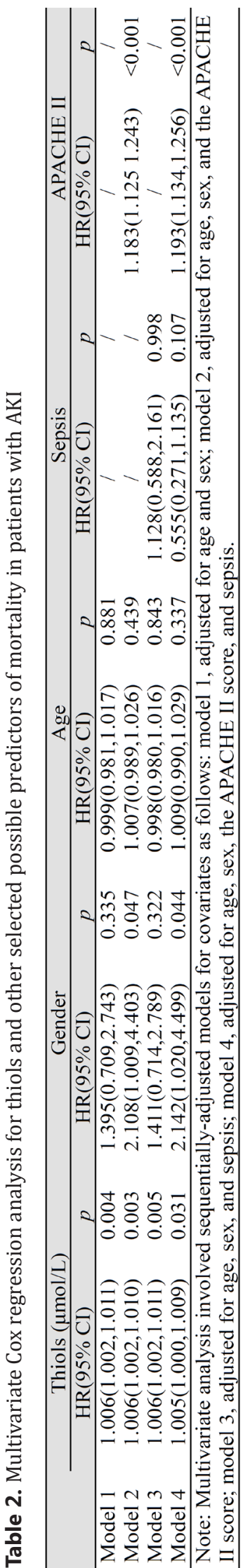

\section{Kidney Blood Press Res 2015;40:623-629}

DOI: $10.1159 / 000368538$

Publisned onIIne: vecember 17, 2015

(C) 2015 S. Karger AG, Basel

www.karger.com/kbr

628

Qian/Fang/Zhu/Ma/Wang/Zheng/Hao/Deng/Zhao/Ding: Serum Thiol Levels in AKI

\section{Discussion}

Thiols are organic sulfur derivatives that are characterized by the presence of sulfhydryl residues. In biological systems, thiols are found in cysteine. and are molecules of low and high molecular weight. In most proteins, cysteine accounts for less than $3 \%$ of the composition of amino acids. However, the chemical versatility of thiol allows this residue to participate in several processes, such as catalysis, signaling, metal complexing, structural stabilization, and antioxidant defense [5]. Some authors have demonstrated that protein thiols, particularly in albumin, constitute a major defense against oxidative stress in plasma $[7,8]$. Plasma thiols are also effective in scavenging free radicals and myeloperoxidasegenerated oxidants. The plasma compartment is characterized by having relatively low concentrations of thiols and by the presence of serum albumin as the most abundant thiols.

In the current study, we found that serum protein thiol levels in patients with AKI and in critically ill patients were significantly lower than those in healthy subjects. Additionally, serum protein thiol levels were positively correlated with serum albumin levels in AKI patients. We did not further investigate the cause of the finding of low thiol levels in in patients with AKI and in critically ill patients. Decreased serum albumin levels may have been one of the main reasons for this finding.

Interestingly, we also found that the 90-day mortality rate was higher in AKI patients with high serum thiol levels than in those with low serum thiol levels. Moreover, serum thiol levels in patients with AKI were correlated with 90-day overall mortality, even following multivariable adjustments for sepsis and the APACHE II score. There are few data on the association between plasma thiol levels and mortality, especially in patients with AKI. Additionally, the association between types of serum antioxidant levels and mortality in critically ill patients still remains controversial.

Serum total antioxidant capacityis a biomarker of antioxidant status. Early in 1999, MacKinnon et al. first demonstrated that serum total antioxidant status and uric acid levels were higher in non-survivors of 50 critically ill patients [9]. They speculated that a higher total antioxidant status level might simply be a response to the degree of renal dysfunction because patients with a worse renal function have higher total antioxidant status and uric acid levels. Chuang et al. reported that total antioxidant capacity levels were elevated in severe sepsis, especially in non-survivors, and were positively correlated with clinical severity [10]. Tsai et al. also reported that plasma total antioxidant capacity levels were significantly higher in non-survivors than in survivors [11]. The authors hypothesized that higher plasma total antioxidant capacity levels in non-survivors are a host response to excessive oxidative stress or a compensating mechanism for exhausted antioxidative components [9] and excessive antioxidant defense, eventually leading to immune dysfunction and poor outcome [11-13]. These hypotheses might partly explain the interesting findings of our study.

Further studies are required to investigate the mechanism underlying the relation between serum protein thiols and 


\section{Kidney \\ Blood Pressure Research}

prognosis in AKI patients. Furthermore, while serum thiols are one of the reasonable measures of antioxidant capacity, additional markers of oxidative stress, such as serum total antioxidant capacity, should also be taken into consideration in further studies.

\section{Conclusions}

In summary, patients with AKI have remarkably low serum protein thiol levels. Elevated thiol levels are associated with 90-day overall mortality in the AKI population. Underlying mechanisms of these findings need to be investigated in further studies.

\section{Disclosure Statement}

The authors declare that they have no competing interests.

\section{Acknowledgements}

We would like to acknowledge the patients for participating in this study.

This study was supported, in part, by grants from the National Natural Science Foundation of China (No: 81070609, 81270850), the Science and Technology Commission of Shanghai Municipality (No: 11441901401), and the National Science and Technology Support Program (No: 2011BAI10B08) (to FD).

\section{References}

-1 Qian J, You HZ, Zhu QY, Ma S, Zhou Y, Zheng Y, Liu JF, Kuang DW, Gu Y, Hao CM, Ding F: Nitrotyrosine level was associated with mortality in patients with acute kidney injury. Plos One 2013;8:e79962.

2 Himmelfarb J, Ikizler TA, Stenvinkel P, Hakim RM: The elephant in uremia: Reflections on oxidant stress as a unifying concept of cardiovascular disease in uremia. Kidney Int 2002;621524-1538.

3 Descamps-Latscha B, Drueke T, Witko-Sarsat V: Dialysis-induced oxidative stress: biological aspects, clinical consequences, and therapy. Semin Dial 2001;14:193-199.

-4 Hansen RE, Roth D, Winther JR: Quantifying the global cellular thiol-disulfide status. Proc Natl Acad Sci USA 2009;106:422-427.

-5 Turell L, Radi R, Alvarez B: The thiol pool in human plasma: the central contribution of albumin to redox processes. Free Radic Biol Med 2013;65:244-253.

-6 Bellomo R, Ronco C, Kellum JA, Mehta RL, Palevsky P, Acute Dialysis Quality Initiative workgroup: The ADQI workgroup Acute renal failure - definition, outcome measures, animal models, fluid therapy and information technology needs: the Second International Consensus Conference of the Acute Dialysis Quality Initiative (ADQI) Group. Crit Care 2004;8:204-212.

7 Tiruppathi C, Finnegan A, Malik AB: Isolation and characterization of a cell surface albumin-binding protein from vascular endothelial cells. Proc Natl Acad Sci USA 1996;93:250-254.

-8 Prinsen BH, de Sain-van der Velden MG: Albumin turnover: experimental approach and its application in health and renal diseases. Clin Chim Acta 2004;347:1-14.

-9 MacKinnon KL, Molnar Z, Lowe D, Watson ID, Shearer E: Measures of total free radical activity in critically ill patients. Clin Biochem 1999;32:263-268.

10 Chuang CC, Shiesh SC, Chi CH, Tu YF, Hor LI, Shieh CC, Chen MF: Serum total antioxidant capacity reflects severity of illness in patients with severe sepsis. Crit Care 2006;10:R36.

11 Tsai K, Hsu TG, Kong CW, Lin K, Lu F: Is the endogenous peroxyl-radical scavenging capacity of plasma protective in systemic inflammatory disorders in humans? Free Radic Biol Med 2000;28:926-933.

12 Pascual C, Karzai W, Meier-Hellmann A, Oberhoffer M, Horn A, Bredle D, Reinhart K: Total plasma antioxidant capacity is not always decreased in sepsis. Crit Care Med 1998;26:705-709.

13 Opal SM: Clinical trial design and outcomes in patients with severe sepsis. Shock 2003;20:295-302. 